\title{
Hospital Pharmacy in Belgium: From Moving Boxes to Providing Optimal Therapy
}

\author{
Thomas De Rijdt and Franciska Desplenter
}

\section{INTRODUCTION}

$\mathrm{T}$ his paper, part of a series on hospital pharmacy across the globe, discusses current hospital pharmacy practice in Belgium. The paper is organized around the building blocks of the World Health Organization's Health Systems Framework and covers the following topics: health information; health system leadership, governance, and financing; health workforce; health service delivery; access to medical products, vaccines, and technology; and future directions.

\section{HEALTH INFORMATION IN BELGIUM}

\section{Health Status Indicators}

An overview of the Belgian population and its demographic indicators up to 2008, including key health status indicators such as live birth and death rates, was presented by Gerkens and Merkur in Table 1.1 of their review of the Belgian health system. ${ }^{1}$ Notably, the fertility rate increased slightly, from 1.7 children per woman 15-49 years old in 1980 to 1.8 in 2007. After declining in the years leading up to 2000, the birth rate also increased slightly, to 11.7 per 1000 population in 2007 . The death rate declined slightly, from 11.5 per 1000 population in 1980 to 9.5 per 1000 population in 2008. Individuals aged 65 years and older made up $17.1 \%$ of the population in 2008 , up from $14.3 \%$ in $1980 .^{1}$

In 2007, life expectancy at birth was 82.6 years for females and 77.1 years for males (see Table 1.4 of Gerkens and Merkur's review of the Belgian health system ${ }^{1}$ ), and these values have been increasing steadily since then (82.8 and 77.3 years, respectively, in 2009 and 83.0 and 78.0 years, respectively, in 2013)..$^{2-4}$ Since 1980, life expectancy has increased by an average of 3 months per year. Conversely, infant mortality declined from 12.1 to 4.0 deaths per 1000 live births over the period 1980 to 2007. ${ }^{1}$ Amenable mortality (deaths avoidable through good quality health care, expressed as standardized death rates per 100000 population) was scored as 96.0 in 2011 and 94.1 in 2012. Preventable mortality (deaths avoidable through public health interventions, also expressed as standardized death rates per 100000 population) was estimated at 214.9 in 2011 and 212.9 in $2012 .^{5}$

\section{Health Information Moving toward eHealth}

In Belgium, detailed information on health and health care is collected in central but isolated databases; in 2009, there were 131 of these standalone systems, and the need to build connections among them was being recognized. ${ }^{1}$ The Law Concerning the Creation and Organization of the eHealth Platform (August 2008) set up a digital eHealth platform for the country to allow electronic exchange of secured data among all holders of healthrelated data. ${ }^{6}$ This platform is a public social security institution providing digital access to all health information and applications through one portal site. Its mission is to promote and support a well-organized exchange of electronic information among all stakeholders, with the necessary guarantees regarding the robustness and availability of data, the protection of patients' and caregivers' privacy, and respect for medical confidentiality. ${ }^{7}$

One medication-related example of data collection is pharmacovigilance reporting, a centralized function of the Federal Agency for Medicines and Health Products for monitoring the safety of medicines. Both patients and health care professionals can report adverse drug reactions, on paper or through online submissions. ${ }^{8}$ This dataset feeds into EudraVigilance, the European pharmacovigilance system. ${ }^{9}$ To date, the number of reports is low. However, a change in culture, driven by accreditation requirements, is being observed as individual hospitals start setting up their own reporting systems for medication incidents. The government has increased awareness of mandatory reporting by assigning official liaison personnel to each hospital, for both medicines and medical devices. The reporting of incidents is increasing, and the greater openness is enabling discussions about incidents and defining actions for improvement.

A second medication-related example of the movement toward eHealth involves initiatives related to seamless or transmural care. A shift from classic inpatient treatment toward 


\section{Table 1. Overview of the Belgian Political Structure ${ }^{12}$}

\begin{tabular}{|c|c|c|c|}
\hline Level & Definition & Authority & Political Structure \\
\hline Federal state & Country of Belgium as a whole & $\begin{array}{l}\text { Foreign affairs, defence, justice, } \\
\text { finance, social security, important } \\
\text { proportion of public health, } \\
\text { internal affairs }\end{array}$ & $\begin{array}{l}\text { Legislative power is executed by } \\
\text { federal parliament, consisting of } \\
2 \text { chambers (Chamber of Deputies, } \\
\text { Senate) and by the king; however, } \\
\text { the king is relieved of all responsibility. } \\
\text { His ministers sign and bear } \\
\text { responsibility for bills put forth by } \\
\text { parliament and royal decrees. The } \\
\text { executive branch lies in the hands of } \\
\text { the federal government. }\end{array}$ \\
\hline ommunities & $\begin{array}{l}\text { Political entities based on Belgium's } \\
3 \text { official languages: } \\
\text { Flemish community, with authority } \\
\text { for the Dutch-language area and } \\
\text { joint authority in the bilingual } \\
\text { Brussels-Capital area } \\
\text { French community, with authority } \\
\text { for the French-language area and } \\
\text { joint authority in the bilingual } \\
\text { Brussels-Capital area } \\
\text { German community, with authority } \\
\text { for the German-language area }\end{array}$ & $\begin{array}{l}\text { All matters that concern Dutch, } \\
\text { French, and German speakers, } \\
\text { respectively (e.g., language, culture, } \\
\text { audiovisual sector, }{ }^{*} \text { education, } \\
\text { care for those in need) }\end{array}$ & $\begin{array}{l}\text { Each community has its own } \\
\text { parliament and government. }\end{array}$ \\
\hline Regions & $\begin{array}{l}\text { Territorial entities: } \\
\text { Flemish Region, coinciding with } \\
\text { the Dutch-language area } \\
\text { Brussels-Capital Region, the bilingual } \\
\text { Brussels-Capital area } \\
\text { Walloon Region, covering the } \\
\text { French- and German-language areas }\end{array}$ & $\begin{array}{l}\text { All matters that concern the interests } \\
\text { of Flemish people, people from } \\
\text { Brussels, and people from Walloons: } \\
\text { economy, employment, housing, } \\
\text { public works, energy, transportation, } \\
\text { environment, and environmental } \\
\text { planning within the respective } \\
\text { territories } \\
\text { Regions also have authority for } \\
\text { international affairs within their } \\
\text { respective domains }\end{array}$ & $\begin{array}{l}\text { Each region has its own parliament } \\
\text { and government. In Flanders, the } \\
\text { region and community authorities are } \\
\text { merged into one government and } \\
\text { one parliament. }\end{array}$ \\
\hline
\end{tabular}

*The audiovisual sector encompasses radio, television, and the film industry.

shorter lengths of stay, day clinics, and outpatient services is continuing. As the intensity of care increases (because of shorter contact time), health care professionals are expected to participate in new tasks and teams. This rise of transmural care has emphasized the need for electronic data exchange among health care professionals. To facilitate communication of information about medication and therapy between first- and second-line care and even within the same level of care, the SAM database ${ }^{10}$ (where SAM = authentic source of medication) was set up, and a "shared pharmaceutical file"11 is being developed. These systems will facilitate a variety of projects, such as medication reconciliation, outpatient antimicrobial therapy, home therapy for parenteral nutrition and antineoplastic drugs, and medical record review for general practitioners (to be performed by hospital pharmacists for the outpatient population).

\section{BELGIAN HEALTH SYSTEM: A CONCISE GUIDE}

\section{Political Landscape}

In Belgium, responsibilities for health policy are shared between the federal (national) level of government and the federated entities (regions and communities) (see Table 1 for an overview of the Belgian political structure ${ }^{12}$ ). The federal level is responsible for the regulation and financing of compulsory health insurance, the determination of minimum standards for hospital services, the financing of hospital budgets and expensive medical devices (e.g., computed tomography and nuclear magnetic resonance scanners), legislation covering professional qualifications, and the registration of pharmaceuticals and their price control. The federated entities are responsible for health promotion, preventive care, care for specific groups (e.g., mothers, children, elderly people) implementation of minimum standards for hospitals and the financing of hospital investment, and implementation of accreditation for hospital pharmacists. ${ }^{13}$ In recent years, there has been a tendency to move decision-making from the federal level toward the federated entities, although financing has remained an important national responsibility. In their Figure 2.1, Gerkens and Merkur ${ }^{1}$ provide an overview of the Belgian health system, highlighting financial flows as well as supervisory relationships.

\section{Health Expenditures}

The budget for public health expenditure in Belgium is fixed by a legislated real-growth norm (set at $4.5 \%$ since 2004). In 2007 , total health expenditure in Belgium was $10.2 \%$ of gross domestic product (GDP), up from $8.6 \%$ of GDP in 2000 and $7.2 \%$ of GDP in 1990 . The growth in health expenditure in 
Belgium, which is similar to that in other Western European countries, can be explained by several factors, including the increasing number of elderly people, higher expectations, growth in real GDP, and increasing implementation of new health technologies. Health expenditure expressed in US dollar purchasing power parity was $\$ 3595$ per capita in 2007 , the sixth highest health expenditure per capita among the 27 European Union (EU) countries at that time (see Gerkens and Merkur, ${ }^{1}$ Figure 3.3).

\section{Financing of the Belgian Health System}

The Belgian health system is based on the principle of social insurance, characterized by horizontal solidarity (between healthy and sick people) and vertical solidarity (based to a large extent on labour incomes), without consideration of an individual's risk factors. ${ }^{1}$ Financing is based mostly on proportional social security contributions related to taxable income and, to a lesser extent, progressive direct taxation, as well as a growing area of alternative financing related to the consumption of goods and services. Participation in the Belgian social security system is compulsory for every Belgian citizen, with contributions from both employers and employees. ${ }^{14}$ In addition to this state-run part of the health care system, each Belgian citizen is obliged to join a private health insurance fund (called a mutuality in Belgium). ${ }^{15}$ Furthermore, in 2001 the Flemish government introduced an additional insurance program for nonmedical care, which is mandatory for anyone over age 25 living in Flanders. The yearly fees are managed by the Flemish government and are meant to support primarily older patients with substantial needs for nonmedical help and service support. ${ }^{16}$ In addition, complementary systems of health insurance are offered both by the mutuality and by private insurance companies for extended care and travel care.

Patients in Belgium participate in health care financing through official copayments and diverse supplements. The main payment mechanism is fee for service, through 1 of 2 systems: direct payment (mainly for ambulatory care), whereby the patient pays for the full cost of the service and then obtains partial reimbursement from the health insurance fund, and a third-party payer system (mainly for ambulatory drugs and hospital care), whereby the health insurance fund pays the provider directly and the patient is responsible only for copayments, supplements, and non-reimbursed services. The third-party payer system can also be applied, under specific conditions, for ambulatory care to improve financial access for vulnerable populations. ${ }^{1}$

\section{Financing of Medications in Belgian Hospitals}

Belgian hospital financing also has a dual financing system according to the type of services provided ${ }^{1,17}:$ a fixed, prospective budget system and a fee-for-service system. Together, these 2 remuneration systems account for almost $80 \%$ of each hospital's revenue. To cover the remaining $20 \%$, hospitals receive additional funding for dispensing of pharmaceutical products for outpatients and inpatients, and gain revenue from other sources. These 4 elements are detailed in Table 2 and Table 3.

\section{Table 2. Description of Financial Elements of Belgian Hospitals}

\section{Financial Element}

Fixed prospective budget system (Budget of Financial Means or BFM)

Based on so-called "justified activities" and "justified beds" with a focus on pathology-weighted length of stay. The case mix of each individual hospital is multiplied by the national average length of stay per pathology group (also called the "justified length of stay"). This budget differs between hospitals and is revised each year.

Consists of 3 major parts, further divided into subparts (see Table 3), which are meant to cover services of accommodation (nursing units), emergency services (anesthesia, sterilization, operating theatre, plaster room), and nursing activities in day hospital stays. Item B5 comprises costs related to the hospital pharmacy for services delivered to inpatients; services for outpatients and day clinics are funded by a profit margin on the product price. Fee-for-service system $\quad \begin{gathered}\text { Medical and medicotechnical services (consultations, laboratory services, medical imaging, } \\ \text { and technical procedures) }\end{gathered}$

Paramedical activities (physiotherapy)

Funding of pharmaceutical In general hospitals: Reimbursement for $75 \%$ of the cost of inpatient medications comes from the products hospital's medication lump sum budget (which is close to covering the real cost); the remaining $25 \%$ is refunded by the health care insurance company via a "fee for product" that is based on the manufacturer's price; no profit margin is allowed. During the period 1983-1989, for non-reimbursed products or medicines dispensed to outpatients, a margin of $21.746 \%$ was billed on top of the manufacturer's price (to a maximum of $€ 7.11$ for the largest package of a medication available on the market). In 1989, this markup (for hospital inpatients) was replaced by a fixed budget (based on historical data) to prevent overconsumption, and in 2006 , this system was replaced by a lump sum budget. In psychiatric hospitals: Medications are funded by a lump sum budget.

Other revenues Specific ambulatory activities, such as day care, dialysis, and rehabilitation (mainly reimbursed per patient via lump sums)

Subsidies for investments from the federated authorities (communities)

Supplements charged to patients

Nonhospital activities, such as commercial operations and homes for the elderly, nursing homes, cafeteria, newspaper shop

Private legacy or corporate grants 
Medication costs are covered through copayments from the patient and the health insurance fund; medicines that are not eligible for reimbursement are fully paid by the patient, whereas for reimbursed medicines, the patient pays a small personal share. The ministry of economic affairs specifies a list price for each product to the manufacturer, and the ministry of social affairs and health care sets the reimbursement prices. Until 1983, medications were billed with a profit of $10 \%$ to cover the operating expenses of the hospital pharmacy. From 1983 to 1989 , this profit margin was set to $21.746 \%$, to a maximum of $€ 7.11$ per package. From 1989 to 2006, this system was replaced by a fixed prospective budget, and reimbursed medications had to be billed at the list price, without mark-up. Since 2006, a lump sum budget has been in place for reimbursed medications. The yearly budget for medications is distributed among all Belgian hospitals as a forfeit per hospital stay according to the hospitals' case mix. The case mix is calculated on the basis of "all patient refined disease related groups" (APR-DRGs) ${ }^{18}$ using coded clinical data from the current year minus 3. Besides the yearly redistribution among the hospitals, the national medication budget declines every year, resulting in a forfeit that is break-even or slightly negative to cover the medication expenses by the hospital. The lump sum must cover $75 \%$ of the acquisition cost; the other $25 \%$ can be billed directly. Exceptional medications (such as antineoplastic drugs, coagulation factors, and gamma globulins) are excluded from the lump sum based on Anatomical Therapeutic Chemical (ATC) codes and can be billed at the list price without mark-up. ${ }^{17}$

Financing of hospital medicines in the future is being explored through various means, including studies of the feasibility of billing cytotoxic drugs on a per-milligram basis, for example. Such measures will stimulate hospitals to cluster patients, to re-engineer processes, and to engage in networking.

\section{HEALTH WORKFORCE}

\section{Hospital Pharmacists}

In 2015, there were 18618 pharmacists in Belgium, reflecting a $3 \%$ annual increase in recent years; of these, $59 \%$ were living in the Dutch-speaking part of the country, $32 \%$ in the Frenchspeaking part, and 9\% in Brussels, the capital region. In addition, about 850 Belgian pharmacists work abroad. Overall, $70 \%$ of the country's pharmacists are women, a proportion that increases to $80 \%$ in the youngest age-group ( $20-35$ years of age). About 3000 of these pharmacists are retired, and the median age of active pharmacists is between 40 and 45 years old.

Of working pharmacists, $90 \%$ are employed in 1 of the country's 4954 community pharmacies (1 pharmacy per 2220 inhabitants). The pharmaceutical industry employs about 750 industry pharmacists in domains such as research, production, regulatory affairs, and marketing. Another 450 practise as pharmacist-clinical biologists. A minority of pharmacists work for the governmental regulatory authorities.

In 2015, Belgium had 1248 recognized hospital pharmacists ( $82 \%$ women, $60 \%$ Flemish), of whom 987 were active in a total of about 150 hospitals. There has been a recent peak in retirements within this group, as most of today's hospital pharmacists started their careers in 1976, when Belgian law was changed to require a pharmacy in every hospital. The minimum number of pharmacists is set by law at 1 per 150 beds (and hospital funding is contingent upon meeting this minimum); however, in practice the mean among Belgian hospitals is about 1 per 100 beds. ${ }^{19-22}$ In ongoing discussions with the government, the Belgian Association of Hospital Pharmacists (also known as ABPHBVZA) has advocated increasing the number of hospital pharmacists to allow provision of clinical pharmacy services on the hospital wards.

Table 3. Composition of Hospital Budgets (According to the BFM)

\begin{tabular}{lcl} 
Component & $\begin{array}{c}\text { Proportion of } \\
\text { Budget (\%) }\end{array}$ & Elements \\
\hline Part A (capital costs) & 8 & A1: investment charges \\
& A2: short-term credit charges \\
& A3: investment charges for some medicotechnical services that are exclusively \\
& financed via the hospital budget (not through fees)
\end{tabular}

$\overline{\mathrm{BFM}}=$ Budget of Financial Means, MRI = magnetic resonance imaging, PET = positron emission tomography. 


\section{Education and Training}

Pharmacists have worked in Belgian hospitals since the early 1950 s, but (as mentioned above) the presence of a pharmacist became mandatory by law only in 1976 . In 1991, a royal decree described for the first time the minimum functions of a hospital pharmacy, and in 2003 the professional title of "hospital pharmacist" was recognized and accredited. Only accredited hospital pharmacists are considered in determining the required ratio of 1 pharmacist per 150 beds; certification is not required for the few "supplementary" pharmacists who work in the hospital pharmacy.

Training for hospital pharmacy is offered as a postgraduate (Master's) program, which was increased in 2012 from 1 to 3 years' duration. Applicants to a Master's program in hospital pharmacy must first complete a university pharmacy degree, consisting of a 3-year baccalaureate program and a 2-year Master's program, the latter of which includes 6 months of training in a community pharmacy. The Master's level training in hospital pharmacy is partly financed by the government. The number of new students each year is limited to 20 for the Walloon region (the French-speaking, southern part of Belgium) and 30 for the Flemish region (the Dutch-speaking, northern part of the country) (see Table 1 for more information on the Belgian regions). Students are selected on the basis of their curricula vitae and personal interviews. Courses cover the topics of management, infection control, pharmacotherapy, hospital technology, and radiopharmaceuticals (see Box 1). ${ }^{23,24}$ The 3-year Master's program in hospital pharmacy includes at least 3500 hours of practical training in distribution, compounding, production, clinical trials, central sterilization, radiopharmaceuticals, clinical pharmacy, and pharmacy and therapeutics committee, as well as preparation of a thesis. To enable all working pharmacists to attain the same skill and knowledge level as new graduates, the professional associations for the Dutch-speaking and Frenchspeaking regions have organized relevant courses, especially on the topics of clinical pharmacy and management, for all their members. ${ }^{24-28}$

\section{Continued Professional Development}

Hospital pharmacists must undertake lifelong learning to maintain their professional recognition, and the government has provided a framework for accreditation specifically for hospital pharmacists. ${ }^{23,24}$ Courses, scientific publications, presentations, posters, attendance at congresses, and a personal development plan can be used to obtain credits. Over each 5-year period, a hospital pharmacist must earn accreditation points in the following domains: organization and management of the hospital pharmacy, control and prevention of infections, pharmacotherapy, hospital technology, and radiopharmaceuticals. Postgraduate education is mainly organized by the professional associations of hospital pharmacists and the universities. The new educational program (established in 2012) and accreditation provide hospital pharmacists with the necessary skills for all of their tasks, so credentialing is not an issue.

\section{Development of Clinical Pharmacy}

Over the past 2 decades, the function of hospital pharmacists has evolved from simply moving boxes and handling supplies to providing medication therapy to patients, with a concomitant shift in focus from the product to the patient. ${ }^{29}$ Key to this evolution has been the introduction of clinical pharmacy services. $^{30-35}$ In the year 2000, some universities and university hospitals started small clinical pharmacy projects, and the first hospital pharmacists started to appear on the wards, building up their experience with individual patients, in collaboration with physicians and nurses. In the years that followed, clinical pharmacy courses were started in the universities, with the development of clinical pharmacy services leading to the establishment of a "network of pharmacy and therapeutics committees" by the government in 2004. The goal of this network is to support the pharmacy and therapeutics committees of individual hospitals and to stimulate sharing of knowledge on guidelines. Introduction of the lump sum budget for medications in 2006 empowered hospital pharmacists, working under the auspices of the

\section{Box 1. Tasks and Responsibilities of Hospital Pharmacists Described in Legislation ${ }^{23,24}$}

- Is responsible for the whole pharmaceutical process, reporting to the Director of Pharmacy, who reports to the CEO

- Orders, receives, and stocks all pharmaceutical products (medication, sterile medical devices, implants, medicinal gas, medicinal nutrition, and point-of-care tests) and guarantees quality, conformity, and traceability

- Compounds and dispenses medications, with assistance from pharmacy technicians

- Counsels patients and gives advice on therapy to other practitioners

- Is an active member of the pharmacy and therapeutics committee, the medical devices committee, the antibiotic committee, and the infection control committee

- Is involved in checking the appropriateness of therapy and the accreditation process

- Is responsible for the quality and conformity of medicinal gas in bulk and cylinders

- Is responsible for outcomes of the central sterilization department

- Is responsible for billing and good economic governance of the pharmacy

$\mathrm{CEO}=$ chief executive officer. 
pharmacy and therapeutics committees, to start clinical pharmacy projects on the rational use of medicines. The government reinvested part of the savings (1.87 million euros over 18 months) realized on the national medication budget toward financing 80 pilot projects in clinical pharmacy. These projects were undertaken on different wards (e.g., geriatrics, cardiology, orthopedics, emergency department, oncology) and focused on a variety of services (e.g., medication reconciliation and discharge information; clinical parameters such as international normalized ratio, renal function, nephrotoxicity, QT-prolongation; record review for selected pharmacological groups [e.g., antibiotics]; and clinical decision support systems for electronic prescription of medicines). Funding for these pilot projects was initially extended until 2014, and from January 2015 onward, funding has been consolidated into the regular financing for all acute care hospitals.

The success of these clinical pharmacy projects led to a shortage of hospital pharmacists with training in clinical pharmacy. As a result, some universities began offering special courses and fellowships until the educational program could be adapted to cover these new needs of hospital pharmacists.

\section{Hospital Pharmacy: Shifting from Supply Function to Provision of Therapy}

The tasks and responsibilities of every health care profession in Belgium are described in legislation, which is due to be updated. Box 1 lists the tasks and responsibilities of hospital pharmacists. In practice, the job description of a typical hospital pharmacist contains a mix of traditional tasks (related to compounding and the supply chain; see Box 1), clinical pharmacy, and a specific domain of expertise (e.g., antineoplastics, pharmacy management, supply chain management, geriatrics, pediatrics). Past projects introducing clinical pharmacy services into the hospital setting have suggested that the involvement of hospital pharmacists in both traditional and clinical tasks is enriching and leads to optimal quality, as these 2 types of task are intertwined, with both serving the goal of patient safety. The past 2 decades have seen the shift from a supply function to the provision of therapy, and hospital pharmacists now represent an integral part of the multidisciplinary patient care team. The implementation of clinical pharmacy services is based on a risk analysis within each hospital. Current clinical pharmacy services cover a mix of central medical record revision, development and implementation of rules for clinical decision support systems, and provision of care on the ward. A similar change in focus has also been noticed in community pharmacies, where a quality system has been mandatory since 2009 and pharmacists are structurally expanding their role as patient counsellors. ${ }^{29}$

The shift in focus from products to patients has been achieved by re-engineering the pharmaceutical process. Risk assessment and task-shifting (to technicians and operators, for example) are freeing up pharmacists' time so that they can engage in higher-level pharmaceutical care, as reflected in publications describing the activities of Belgian hospital pharmacists. ${ }^{26,30-36}$ As a result, hospital pharmacists must delegate some of their responsibilities to support services personnel, through a service-level agreement. Examples are maintenance of pipelines and tanks for medical gases, transport of medications, and management of ward stock for sterile medical devices such as syringes and needles. Compounding is eligible for contracted outsourcing to colleagues or commercial compounding centres, but the dispensing pharmacist remains responsible for the quality and conformity of the preparation. ${ }^{37}$

\section{Pharmacy Technicians}

Pharmacy technicians are allowed to dispense and compound medications under the supervision of a hospital pharmacist, who holds ultimate responsibility. There is a legal maximum of 3 technicians per pharmacist. The role of pharmacy technicians was recognized by royal decree in 1997 , and their training became regulated. Training is at the level of secondary education and includes 300 hours of practical training in either the community or a hospital. However, training is not specific to the hospital setting, and post-qualification on-the-job training is also required (e.g., aseptic compounding, single-dose distribution, specific hospital medications). Recently, the governmental regulatory authorities have organized a survey asking pharmacists about their needs in relation to the level of training of pharmacy technicians; the information from this survey will be used to update the minimal educational program for pharmacy technicians.

\section{Other Pharmacy Staff}

Hospital pharmacists may authorize other staff members to carry out any task within their competence (e.g., administrative, warehouse, financial). Large hospitals typically hire industry pharmacists to manage the compounding process. They can also operate as qualified persons for phase 1 and phase 2a clinical trials, as required by good manufacturing practice. All staff involved in clinical trials require biennial accreditation in good clinical practice. ${ }^{36,38}$

\section{Physicians}

Medical doctors have a monopoly on prescribing in Belgium, whereas dentists and midwives have limited prescribing rights. To optimize the health care process, there may be an opportunity in the future to allow hospital pharmacists to alter doses or routes of administration for specific programs or therapies. In some hospitals, nurses or doctors in training are allowed to prepare prescriptions before validation by the attending physician. In the hospital setting, electronic validation of prescriptions is allowed. ${ }^{26}$ 


\section{Nurses}

In addition to medical doctors and pharmacy staff, nurses are a third group of important players in medication management. Only nurses and physicians are permitted to administer medications to patients in a hospital setting. In some settings, patients are allowed, with appropriate training and monitoring by a nurse, to manage their own medications. Nurses can specialize in specific domains such as HIV and wound management. In the operating theatre, a specialized nurse assists the hospital pharmacist in managing decentralized stocks of implantable medical devices. ${ }^{26}$

\section{INVESTING IN PROFESSIONAL HEALTH SERVICE DELIVERY}

\section{Prescribing}

Most hospitals in Belgium are implementing or are already using a computerized physician order entry system, some with basic or advanced clinical decision support on board and one with hospital-wide bedside scanning. This trend is supported by the government, which is promoting and providing an eHealth platform where summaries of medical records can be exchanged among the patient's health care providers. Other eHealth services include a trusted third-party time-stamping service to guarantee the authenticity of electronic prescriptions; a medication database known as SAM ("authentic source of medication") that allows systems to communicate about medications without using brand names; KHMER, a medical data standard for exchanging structured clinical information; and RCT, a central register for tracing implantable medical devices. ${ }^{7,39-42}$

\section{Medication Distribution and Compounding}

All medications for in-hospital use must be dispensed by the hospital pharmacy. Once discharged, patients must get their medications from community pharmacies, with a few exceptions (e.g., erythropoietin, oral anticancer drugs) that must be dispensed by a hospital pharmacist. Hospitals cannot offer community pharmacy services, although the first private community pharmacy on hospital grounds was introduced in July 2014, and hospital administrators are now brainstorming about future "polyclinic pharmacies" to facilitate transmural care.

Most hospitals use a mixed drug distribution system, with ward stocks for common medications and patient-level dispensing from the central pharmacy. Harmful and/or expensive drugs are generally dispensed from the central pharmacy to ensure additional prescription checks, both for patient safety reasons and to minimize financial risk for the hospital. Only a few hospitals have a 24-hour distribution system in place, and this number is not expected to increase. Electronic cupboards are often used in the emergency department, to hold emergency stocks of medications, to dispense controlled substances, and recently to store expensive medical devices in the operating theatres. Robots and electronic cupboards are increasingly used, although to date they have insufficient capacity for larger hospitals. ${ }^{43}$

Reconstitution of medications before administration is performed by nurses on the ward, with increasing availability of ready-touse medication. Antineoplastic drugs and other potentially hazardous drugs can be prepared in the hospital pharmacy or can be outsourced to other hospital pharmacists or, recently, to commercial compounding centres. Compounding of non-hazardous drugs (e.g., capsules, syrups, dermatology products, sterile preparations) can be done only in the hospital pharmacy. Implementation of the Pharmaceutical Inspection Co-operation Scheme (PIC/S) PE 010-4 guideline as a standard is expected soon. ${ }^{44}$

Almost weekly, hospital pharmacists in Belgium must deal with medication shortages. ${ }^{45}$ In most cases, continuity of therapy can be guaranteed by using alternatives found on the Belgian or international market, but these shortages lead to a significant workload, to which each hospital easily devotes 0.5 full-time equivalent. Besides the logistical burden, there is an increased risk to the patient, as alternative products may have different strengths and concentrations, and thus are subject to medication errors. Since publication of the "sunset clause" 46 in 2011, hospital pharmacists are legally allowed to import medications when they are not available on the national market, but such importation carries a financial risk for both patients and hospitals, as these drugs are not eligible for reimbursement. To control the problem, the government created a task force with all stakeholders (government, pharmacists, hospital pharmacists, pharmaceutical industry), which can advise on allowing a derogation for import by the wholesaler-distributor and reimbursement to the patient and which can set up an "early warning system". Most hospital pharmacists also include a "make-or-buy" analysis, in case no affordable alternative is available.

\section{Investing in Quality Systems}

In 2002, the first of 9 hospital pharmacies became ISO 9001 certified. To share this philosophy of certification with all members, the Belgian Association of Hospital Pharmacists published the first edition of a peer review checklist in 2006, updated to its fourth edition in 2014. ${ }^{21}$ The fifth edition (expected in 2017) will include quality accreditation standards to help hospital pharmacists preparing for accreditation or reaccreditation by the Joint Commission International (JCI), Qmentum/NIAZ (Nederlands Instituut voor Accreditatie in de Zorg [Netherlands Institute for Accreditation in Healthcare]), or other International Society for Quality in Healthcare-accredited organizations. In 2008, the first Belgian hospital became Qmentum/NIAZ-accredited, followed by the first JCI accreditation in 2010. Currently, over 90\% of all Flemish hospitals are working toward accreditation (mostly through the JCI or 
Qmentum/NIAZ), as suggested by the government. Although not required by the Walloon government, many hospitals in that region are also preparing for accreditation. In addition to accreditation, the hospital sector uses various quality indicators (e.g., quality of prescription, handling of high-alert medications) to score hospitals, and these results are made available to the public on the website of the Flemish government. ${ }^{47}$

\section{PRACTICAL EXAMPLES OF THE ORGANIZATION OF BELGIAN HEALTH CARE}

\section{Access to Vaccines}

Vaccination policy is a shared responsibility of the Federal Ministry of Health and Social Affairs, as well as the regional ministries of health. The National Vaccination Committee is responsible for vaccination recommendations. The regional authorities are responsible for implementing and promoting the recommended vaccination programs and are in charge of purchasing most of the traditional infant and adolescent vaccines. Children up to 3 years of age are invited to public baby clinics (known as "Child and Family" in Flanders and the "Birth and Children Office" in the French community) to take advantage of the vaccination program, which is free (no charge for the vaccines or for consultation with a general practitioner). Polio vaccination is the only mandatory vaccination in Belgium. Since 1999 the "Child and Family" clinics have been registering every administered vaccine in Vaccinnet, an online vaccination database. ${ }^{48}$ For school-age children (up to about 15 years of age, according to the current vaccination scheme), a school health system organizes preventive consultations and offers the vaccinations recommended for that age group; this program is also free of charge. The school health system achieves $60 \%-80 \%$ coverage, with general practitioners having a complementary role to cover the remaining $20 \%-40 \%$. Beyond school age, there is no public health service offering vaccinations, except for populations seen by occupational health physicians. Some of the occupational vaccines are offered free of charge or through the Fund for Occupational Diseases (e.g., hepatitis vaccines) or through the employer (e.g., travel vaccines for employees who must travel for work or influenza vaccine for hospital employees). Travel clinics provide specific counselling and vaccination services. ${ }^{49}$

\section{Procurement Procedures}

In 2012, European Directive 2004/18/EC was fully implemented, obliging hospitals to apply public procurement procedures to all of their contracts. This new law details the conditions that contracting authorities should apply, concerning pricing and contracting of goods, services, and works. The directive has the following objectives: tenders must be public, so that all suppliers are able to participate; procedures must be transparent, with objectivity of selection and award criteria; decisions should be reasoned; and, last but not least, all suppliers must be treated equally. To support Belgian hospital pharmacists and to assist in implementation of the new law, the Belgian Association of Hospital Pharmacists has organized workshops and information sessions, and has collected and disseminated information and examples of tenders (even at the cross-border level) to all members. ${ }^{50}$ Experience is growing rapidly, but pharmacists have many concerns, given that public procurement for medicines is demanding in terms of both time and human resources and these factors may ultimately outweigh the financial benefits. Public tendering can be very effective for medical devices, which can be purchased all over the world, so long as they have a CE (Conformité européenne) label and so long as the authorities are notified. Public procurement of medicines from other European countries is limited, because of a prohibition against importing drugs that are available on the Belgian market, with reimbursement being granted only for drugs licensed in Belgium. These conditions limit the number of providers and lower the market effect of tendering, while protecting the official Belgian market from counterfeit medicines.

\section{Medical Devices}

Another example within the field of hospital logistics is the notification and traceability of implantable medical devices. Together with the CE certificate, these functions are mandatory to allow the use of devices in patients and for billing and reimbursement. Companies that market implants in Belgium must provide notification of their products directly to a national database. Implants that are subject to notification requirements but for which notification has not occurred cannot be paid for by patients or insurance companies. All implantation and removal procedures must be recorded in the database, which contains details of all long-term implants and invasive medical devices. This compulsory notification enables the development of an inventory of all implants in the country, facilitates future recalls in case of incidents, and provides data for evaluation of quality, which are key to preventive recalls. ${ }^{51}$

\section{New Technologies}

The emergence of biosimilar medicines should facilitate affordable access to treatments and enhance the financial sustainability of national health systems. However, Belgium has one of the lowest rates of uptake of biosimilar medicines in Europe. ${ }^{52}$ Only the prescriber can decide to switch from an original product to a biosimilar medicine (or vice versa); pharmacists do not have substitution rights for any medicine, including biosimilar medicines. ${ }^{53}$ The current Federal Minister of Health is planning a campaign to increase the uptake of these compounds and has signed an agreement with all related health professional organizations and the pharmaceutical industry. ${ }^{54}$ 


\section{FUTURE DIRECTIONS AND CONCLUSIONS}

In the quest for optimal quality and patient safety, the development of new technologies, combined with resource limitations, increasingly forces the pharmaceutical process to evolve. In this process re-engineering, there is room for "task purification", creation of new tasks and services, lean management, risk analysis, seamless care, pharmaceutical care, and other streamlining efforts, as well as different modes of financing and the obligation to make choices. This evolution is also reflected in the draft of a new royal decree describing the guidelines for good hospital pharmacist practices, which proposes the PIC/S PE 010-4 guideline $e^{44}$ as the standard (to ensure compliance with the EU recommendation for qualitative compounding). According to these guidelines, medication for inpatients should be dispensed in single-dose packaging, and traceability is required for all drugs and implantable medical devices. For medical devices, a national register is already in place, and all hospitals will be asked to use the register starting in 2016 . The new decree will also explicitly set out the responsibilities of hospital pharmacists with regard to the central sterilization unit, and will require pharmacists to review each new therapy before dispensing.

The European falsified medicines directive, ${ }^{55,56}$ published by the EU on February 9, 2016, will require all pharmacists to check the serial number of secondary packaging against a national repository at the moment of dispensing. Given the use of singledose dispensing in the hospital setting, an efficient method of checking out boxes should be developed. ${ }^{8}$

In 2014, the Belgian Minister of Health presented a 5-year road map for reorganizing health care, to guarantee safety and quality at an affordable cost. According to this plan, the eHealth platform is crucial to facilitate interdisciplinary and seamless health care. Hospitals are encouraged to engage in networking within centres of excellence, and financing is being changed in a way that will involve all stakeholders. Reimbursement for health care will be further consolidated in the lump sum system, and expensive drugs will be reimbursed on a per-milligram basis, rather than per dispensed vial. Clinical pharmacy services will be supported, as they can be cost-effective if well planned and implemented. Perhaps the time is right to think about granting restricted prescriber rights to hospital pharmacists, who can manage the dosing of medications in relation to therapeutic drug monitoring and patient parameters, such as renal function and antibiograms. Risk stratification of patients will be increasingly supported by artificial intelligence and data-mining, which will result in personalized clinical rules and alerts to guide health care professionals.

A huge evolution is taking place in Belgium, and hospital pharmacy today cannot be compared to hospital pharmacy 5 years ago or hospital pharmacy in 5 years' time. However, with the new education program in place, hospital pharmacists are prepared for a bright future.
References

1. Gerkens S, Merkur S. Belgium: health system review. Health Syst Transit. 2010;12(5):1-266, xxv. Available from: www.euro.who.int/_data/assets/ pdf_file/0014/120425/E94245.PDF

2. In the spotlight: Life expectancy in the European Union. Brussels (Belgium): Federal Government of Belgium, Statistics Belgium; 2013 [cited 2016 Feb 24]. Available from: http://statbel.fgov.be/en/statistics/organisation/ statistics_belgium/dissemination/statbel/in_the_spotlight_archives/in_the_ spotlight_2011/20111103_life_expectancy_in_the_European_Union_arch ives.jsp

3. OECD better life index: Belgium. Paris (France): Organisation for Economic Co-operation and Development; [cited 2016 Feb 24]. Available from: www.oecdbetterlifeindex.org/countries/belgium/

4. World health rankings. Leduc Media; 2014 May [cited 2016 Feb 24]. Available from: www.worldlifeexpectancy.com/belgium-life-expectancy

5. Eurostat statistics explained: amenable and preventable deaths statistics. Brussels (Belgium): European Commission, Eurostat; 2015 Oct 21 [cited 2016 Feb 24]. Available from: http://ec.europa.eu/eurostat/statisticsexplained/index.php/Amenable_and_preventable_deaths_statistics

6. [Law concerning the creation and organization of the eHealth platform, containing various provisions]. Brussels (Belgium): Federal Government of Belgium, Department of Social Security; 2008 [cited 2016 Apr 8]. Available from: www.ejustice.just.fgov.be/cgi_loi/change_lg.pl?language $=$ nl $\&$ la $=$ N\&table_name=wet\&cn=2008082153. In Dutch and French.

7. e-Health [website]. Brussels (Belgium): Federal Government of Belgium; 2016 [cited 2016 Feb 24]. Available from: https://www.ehealth.fgov.be/ $\mathrm{nl} /$ home. In Dutch.

8. Wat is geneesmiddelenbewaking (farmacovigilantie) en hoe kan u eventuele bijwerkingen melden? [What is pharmacovigilance and how to report possible side effects of medication]. Brussels (Belgium): Federaal agentschap voor geneesmiddelen en gezondheidsproducten (FAGG) [Federal Agency for Medicines and Health Products]; 2012 Nov 7 [cited 2016 Feb 24]. Available from: www.fagg-afmps.be/nl/public_information/geneesmiddel enbewaking/. In Dutch.

9. EudraVigilance: pharmacovigilance in the European economic area [website]. London (UK): European Medicines Agency; [cited 2016 Feb 24]. Available from: https:/eudravigilance.ema.europa.eu/highres.htm

10. Stichele RV. Authentieke bron Geneesmiddelen voor het ziekenhuis [Authentic database for medications for hospital use] [slide presentation]. Ghent (Belgium): Centre belge d'information pharmacothérapeutique; 2008 Dec 5 [cited 2016 Feb 24]. Available from: http://health.belgium.be/ internet2Prd/groups/public/@public/@dg1/@acutecare/documents/ie2divers/ 15860560_fr.pdf. In Dutch.

11. Rol en kerntaken: Gedeeld Farmaceutisch Dossier [Role and core tasks: shared pharmaceutical record]. Brussels (Belgium): Association pharmaceutique belge; 2016 [cited 2016 Feb 24]. Available from: www.apb.be/ $\mathrm{nl} /$ corp/de-apotheker/ROL-EN-KERNTAKEN/Pages/gedeeldfarmaceutisch-dossier.aspx. In Dutch.

12. Structure of the Belgian Federal State. Brussels (Belgium): Belgian Presidency of the Council of the European Union; [cited 2016 Feb 24]. Available from: www.eutrio.be/structure-de-letat-federal-belge. Not publicly available.

13. Segaert C. The health care system in Belgium [slide presentation]. Rijksinstituut voor ziekte en invaliditeitsverzekering (RIZIV) [National Institute for Health and Disability Insurance]; 2013 Nov 26 [cited 2016 Feb 24]. Available from: www.coopami.org/en/countries/countries/south_korea/ projects/2013/pdf/2013112602.pdf

14. Social security in Belgium. Brussels (Belgium): Federal Government of Belgium; 2016 [cited 2016 Feb 24]. Available from: www.belgium.be/ en/family/social_security_in_belgium/

15. Ziekteverzekering [Health insurance]. Brussels (Belgium): Flemish Government; [cited 2016 Feb 24]. Available from: www.vlaanderen.be/nl/ gezin-welzijn-en-gezondheid/gezondheidszorg/ziekteverzekering. In Dutch.

16. Vlaamse sociale bescheming [Flemish social protection]. Brussels (Belgium): Flemish Government; 2016 [cited 2016 Apr 10]. Available from: www. vlaamsezorgverzekering.be/. In Dutch.

17. Cuypers R, Degraeve K, Tuerlinckx M, Willems L. De financiering van de ziekenhuizen [Financing hospitals]. Mechelen (Belgium): Wolters Kluwer Belgium; 2013. 180 pp. 
18. Averill RF, Goldfield N, Hughes IS, Bonazelli J, McCullough EC, Steinbeck $\mathrm{BA}$, et al. All patient refined diagnosis related groups (APR-DRGs). Version 20.0. Methodology overview. Wallingford (CT): 3M Health Information Systems; 2003 [cited 2016 Feb 24]. Available from: https://www. hcup-us.ahrq.gov/db/nation/nis/APR-DRGsV20MethodologyOver viewand Bibliography.pdf

19. Vereniging der Apothekers van de Pharmaceutische Industrie/Union des Pharmaciens de l'Industrie Pharmaceutique (UPIP-VAPI) [home page]. Meerbeke (Belgium): UPIP-VAPI; [cited 2016 Feb 24]. Available from: www.upip-vapi.be/

20. Association pharmaceutique belge [home page]. Brussels (Belgium): The Association; [cited 2016 Feb 24]. Available from: www.apb.be/

21. Société belge des pharmaciens spécialistes en biologie clinique [home page]. Brussels (Belgium): The Society; [cited 2016 Feb 24]. Available from: www.abpb.org/

22. Association belge des pharmaciens hospitaliers [home page]. The Association; [cited 2016 Feb 24]. Available from: www.hospitalpharmacist belgium.eu/

23. [Royal decree setting out the procedure for professional degree and accreditation of hospital pharmacists]. Federal Government of Belgium, Department of Health, Food Chain Safety and Environment; 2012 Dec 3 [cited 2016 Feb 24]. Available from: www.ejustice.just.fgov.be/cgi_loi/ change_lg.pl?language $=n l \& l a=N \&$ table_name $=w e t \& c n=2012102214$. In Dutch and French.

24. [Ministerial order stating the criteria for accreditation of professional hospital pharmacists]. Federal Government of Belgium, Department of Health, Food Chain Safety and Environment; 2012 Oct 22 [cited 2016 Feb 24]. Available from: www.ejustice.just.fgov.be/cgi_loi/change_lg.pl?language=nl\&la=N\& table_name=wet $\& c n=2012102213$. In Dutch and French.

25. [Master's in hospital pharmacy]. Leuven (Belgium): KU Leuven; [cited 2016 Feb 24]. Available from: https://pharm.kuleuven.be/ziekenhuis/. In Dutch.

26. [Royal decree no. 78 concerning the practice of health care professions]. KB 78. Federal Government of Belgium; 1967 Nov 10 [cited 2016 Feb 24]. Available from: www.ejustice.just.fgov.be/cgi_loi/change_lg.pl?language= nl\&la $=N \& c n=1967111008 \&$ table_name=wet. In Dutch and French.

27. [Royal decree setting out the standards that a hospital pharmacy must satisfy for accreditation]. KB 04/03/1991. Federal Government of Belgium, Department of Public Health and Environment; 1991 Mar 4 [cited 2016 Feb 24]. Available from: www.ejustice.just.fgov.be/cgi_loi/change_lg.pl? language $=n l \& l a=N \&$ table_name $=w e t \& c n=1991030433$. In Dutch and French.

28. [Royal decree setting out the procedure for accreditation of professional hospital pharmacists]. Federal Government of Belgium, Department of Health, Food Chain Safety and Environment; 2012 Oct 22 [cited 2016 Feb 24]. Available from: www.ejustice.just.fgov.be/cgi_loi/change_lg.pl? language $=$ nl\&la=N\&cn=2012102214\&table_name=wet. In Dutch and French.

29. Health at a glance 2015: OECD indicators. Paris (France): OECD Publishing; 2015 [cited 2016 Feb 24]. Available from: http://dx.doi.org/10.1787/ health_glance-2015-en

30. Somers A, Robays H, De Paepe P, Van Maele G, Perehudoff K, Petrovic M. Evaluation of clinical pharmacist recommendations in the geriatric ward of a Belgian university hospital. Clin Interv Aging. 2013;8:703-9.

31. Spinewine A, Swine C, Dhillon S, Lambert P, Nachega JB, Wilmotte L, et al. Effect of a collaborative approach on the quality of prescribing for geriatric inpatients: a randomized, controlled trial. J Am Geriatr Soc. 2007; 55(5):658-65.

32. De Winter S, Vanbrabant P, Spriet I, Desruelles D, Indevuyst C, Knockaert $\mathrm{D}$, et al. A simple tool to improve medication reconciliation at the emergency department. Eur J Intern Med. 2011;22(4):382-5.

33. Cornu P, Steurbaut S, Gentens K, Van de Velde R, Dupont AG. Pilot evaluation of an optimized context-specific drug-drug interaction alerting system: a controlled pre-post study. Int J Med Inform. 2015;84(9):617-29.

34. Petrovic M, Somers A, Onder G. Optimization of geriatric pharmacotherapy: role of multifaceted cooperation in the hospital setting. Drugs Aging. 2016; 33(3):179-88
35. Claus BO, Colpaert K, Steurbaut K, De Turck F, Vogelaers DP, Robays H, et al. Role of an electronic antimicrobial alert system in intensive care in dosing errors and pharmacist workload. Int J Clin Pharm. 2015;37(2):387-94.

36. [Royal decree approving new instructions for physicians, pharmacists and druggists]. KB 1885. Federal Government of Belgium, Department of Public Health and Environment; 1885 [cited 2016 Feb 24]. Available from: www.ejustice.just.fgov.be/cgi_loi/change_lg.pl?language $=$ nl\&la $=N \& c n=188$ 5053130\&table_name=wet. In Dutch and French.

37. [Royal decree regulating pharmacies and medication depots in health care facilities]. KB 1978. Federal Government of Belgium; 1978 Oct 19 [cited 2016 Feb 24]. Available from: www.ejustice.just.fgov.be/cgi_loi/change_ lg.pl?language $=n l \& l a=N \& c n=1978101930 \&$ table_name $=$ wet. In Dutch and French.

38. [Royal decree relating to the professional designation and required qualifications for the practice of the profession of pharmaceutical technical assistant, including the list of activities that can be assigned by a pharmacist]. KB 1997. Federal Government of Belgium, Department of Social Services, Public Health and Environment; 1997 Feb 5 [cited 2016 Feb 24]. Available from: www.ejustice.just.fgov.be/cgi_loi/change_lg.pl?language $=$ nl\&la $=$ N\&table_name=wet\&cn=1997020545. In Dutch and French.

39. De Rijdt T. Computerised physician order entry and bedside scanning as a tool to improve patient safety. Eur J Hosp Pharm. 2012;19(3):320-1.

40. SAM2: Logical data dossier 3. SMALS; 2013 Dec 16 [cited 2016 Feb 24]. Available from: https://www.ehealth.fgov.be/sites/default/files/civics/manual/ sam2_-_logical_data_dossier_v2.3.pdf

41. KMEHR: Kind messages for electronic healthcare record - Belgian implementation standard. Brussels (Belgium): Federal Public Service, Social Security; [cited 2016 Feb 24]. Available from: https://www.ehealth.fgov.be/ standards/kmehr/

42. Cookbook eHealth central registry traceability V1 RCT. Version 1.0. Brussels (Belgium): 2015 Jul 13 [cited 2016 Feb 24]. Available from: https://www.ehealth.fgov.be/sites/default/files/fonctionnalit\%C3\%A9s/ cookbook/rct_cookbook_v1_dd_20150713.pdf

43. Actua-Zorg: robots spelen apotheek in AZ Damiaan [New topics in care: Robots are running the pharmacy in Damian Acute Care Hospital] [video]. [cited 2016 Feb 24]. Available from: https://www.youtube.com/watch?v= oP5DNbB8RoY

44. PIC/S Secretariat. PIC/S guide to good practices for the preparation of medicinal products in healthcare establishments. PE 010-4. Geneva (Switzerland): Pharmaceutical Inspection Convention, Pharmaceutical Inspection Co-operation Scheme; 2014 Mar 1 [cited 2016 Apr 11]. Available from: www.picscheme.org/publication.php

45. Medicine shortages in European hospitals: the evidence and case for action. Brussels (Belgium): European Association of Hospital Pharmacists; 2014 Oct [cited 2016 Feb 24]. Available from: www.eahp.eu/sites/default/ files/shortages_report05online.pdf

46. [Law concerning medications]. 1964 Mar 25 [cited 2016 Feb 24]. Available from: www.ejustice.just.fgov.be/cgi_loi/change_lg.pl?language=nl\&la=N\& $\mathrm{cn}=1964032530 \&$ table_name=wet. In Dutch and French.

47. Kwaliteitsindicatoren voor algemene ziekenhuizen [Quality indicators for acute care hospitals]. Brussels (Belgium); [cited 2016 Feb 24]. Available from: www.zorg-en-gezondheid.be/kwaliteitsindicatorenziekenhuizen/

48. Vaccinnet. Brussels (Belgium): Flemish Government, Child \& Family; 2016 [cited 2016 Apr 10]. Available from: https://www.vaccinnet.be/

49. Van Damme P, Lernout T, Swenne B, Theeten H. Summary report on immunization programs in Belgium. [cited $2016 \mathrm{Feb}$ 24]. Available from: http://venice.cineca.org/documents/belgium_ip.pdf

50. Swartenbroekx J. Public procurement. Eur J Hosp Pharm. 2012;19(3):326.

51. Wouters D. Notification of implants. Eur J Hosp Pharm. 2012;19(3):323.

52. Lepage-Nefkens I, Gerkens S, Vinck I, Piérpart J, Hulstaert F, Farfan-Portet MI. Barriers and opportunities for the uptake of biosimilar medicines in Belgium. KCE report 199. Brussels (Belgium): Belgian Health Care Knowledge Centre; 2013 Mar 28 [cited 2016 Feb 24]. Available from: https://kce.fgov.be/sites/default/files/page_documents/KCE_199_201213-HSR_Biosimilars_report_0.pdf 
53. Biosimilars. Brussels (Belgium): Federaal agentschap voor geneesmiddelen en gezondheidsproducten (FAGG) [Federal Agency for Medicines and Health Products]; 2014 Jan 22 [cited 2016 Feb 24]. Available from: www.fagg-afmps.be/nl/MENSELIJK_gebruik/geneesmiddelen/ geneesmiddelen/procedures_vhb/Registratie_procedures/Biosimilars/

54. Convenant "Doorstart voor biosimilaire geneesmiddelen in Belgie" [Covenant: Startover for biosimilar medicines in Belgium]. Rijksinstituut voor ziekte en invaliditeitsverzekering (RIZIV) [National Institute for Health and Disability Insurance]; [cited 2016 Feb 24]. Available from: www.inami.fgov.be/nl/themas/kost-terugbetaling/door-ziekenfonds/ geneesmiddel-gezondheidsproduct/geneesmiddel-voorschrijven/Paginas/ biosimilaire-geneesmiddelen.aspx\#.Vta-aFjSkdU

55. Commission Delegated Regulation (EU) 2015/161 of 2 October 2015 supplementing Directive 2001/83/EC of the European Parliament and of the Council by laying down detailed rules for the safety features appearing on the packaging of medicinal products for human use. Brussels (Belgium): European Parliament; [cited 2016 Feb 24]. Available from: http://ec. europa.eu/health/files/eudralex/vol-1/reg_2016_161/reg_2016_161_en.pdf

56. Medicinal products for human use: falsified medicines. Brussels (Belgium): European Commission, Public Health; [cited 2016 Feb 24]. Available from: http://ec.europa.eu/health/human-use/falsified_medicines/index_en.htm
Thomas De Rijdt, PharmD, Accredited Hospital Pharmacist, is the Assistant Head of Pharmacy with the Pharmacy Department, University Hospitals Leuven, Leuven, Belgium. He is also Vice President of the Belgian Association of Hospital Pharmacists (ABPH-BVZA).

Franciska Desplenter, PharmD, Accredited Hospital Pharmacist, PhD, is Head of the Pharmacy Department, University Psychiatric Hospitals Katholieke Universiteit Leuven (Campus Kortenberg), Kortenberg, Belgium. She is also a member of the Belgian Association of Hospital Pharmacists (ABPH-BVZA) and past president of the European Society of Clinical Pharmacy.

Competing interests: None declared.

Address correspondence to:

Franciska Desplenter

Z.org KU Leuven

University Psychiatric Hospitals Katholieke Universiteit Leuven

Pharmacy Department, Campus Kortenberg

Leuvensesteenweg 517

3070 Kortenberg, Belgium

e-mail: siska.desplenter@bvza-abph.be 